\title{
Medical Treatment of Fibroid to Decrease Rate of Hysterectomy
}

\author{
Mohamed Y. Abdel-Rahman', \\ Mohamed Sabry ${ }^{1,2}$ and Ayman Al-Hendy ${ }^{2}$ \\ ${ }^{1}$ Department of Obstetrics and Gynecology, Sohag University Hospitals, Sohag, \\ ${ }^{2}$ Center for Women's Health Research, Department of Obstetrics and Gynecology, \\ Meharry Medical College, Nashville, Tennessee, \\ ${ }^{1}$ Egypt \\ 2USA
}

\section{Introduction}

Uterine leiomyomas are the most common benign pelvic tumors in women [1, 2]. They are monoclonal tumors of the smooth muscle cells of the myometrium and consist of large amounts of extracellular matrix that contains collagen, fibronectin and proteoglycan [2, 3]. A thin pseudocapsule that is composed of areolar tissue and compressed muscle fibers usually surrounds the tumors [4]. Leiomyomas may enlarge to cause significant distortion of the uterine surface or cavity. Although they are benign, they commonly result in severe symptoms, such as heavy, irregular and prolonged menstrual bleeding as well as anemia. Uterine leiomyomas have also been associated with numerous other medical disorders, such as infertility, recurrent abortion and preterm labor [5]. These clinical complications negatively impact women's health. Uterine leiomyomas are the most cited indication for more than 600,000 hysterectomies performed in the US annually, and this major surgery is associated with morbidity and mortality as well as a huge economic impact on healthcare delivery systems that is estimated to be approximately $\$ 2.2$ billion/year [6].

\section{Current medical treatment options for uterine leiomyomas}

Treatment options for leiomyoma vary. Treatment strategies are typically individualized based on the severity of the symptoms, the size and location of the leiomyoma lesions, the patient's age and their chronological proximity to menopause, and the patient's desire for future fertility. The usual goal of therapy is the relief of the symptoms (which include abnormal uterine bleeding, pain, and pressure). The treatment options range from the use of acupuncture (ancient Chinese method) to the total removal of the uterus and its myoma contents [7]. The gold standard of leiomyoma treatment is surgical intervention. Hysterectomy is the definitive surgical operation, but myomectomy is still commonly performed especially in women who desire future fertility. More recently developed techniques, which include uterine artery embolization (UAE), magnetic resonance-guided focused-ultrasound surgery (MRgFUS) and myolysis, are emerging as minimally invasive 
alternative procedures. To date, there is no definitive therapeutic agents for the treatment of uterine leiomyomas, which is a reflection of the dearth of randomized clinical trial data demonstrating the effectiveness and safety of medical therapies in the management of symptomatic leiomyomas [8]. This chapter will focus on medical treatment options for uterine leiomyoma as a promising tool to decrease the rate of hysterectomy with its burden to the health system as well as the patients.

\subsection{COCs and progestins}

Combined oral contraceptive hormones have been widely tried by physicians to reduce the blood loss associated with uterine fibroids. A large prospective study including more than 3000 patients with fibroids found a positive correlation between the early use of COCs (before 17 years) and the incidence of fibroid [9]. Other controlled trials showed no association between the use of COCs and the development of uterine fibroids [10,11].

The effect of COcs and progestins in reducing the size of fibroids is not documented [12-14].

\section{Levonorgestrel-releasing intrauterine system}

The levonorgestrel-releasing intrauterine system (LNG) is one of the most effective treatments in reducing menorrhagia. In a small randomized trial; LNG decreased the blood loss significantly after 6 weeks of application in women with menorrhagia and fibroid [15]. However; it did not decrease the myoma size.

\subsection{Promising GnRH antagonist (elagolix)}

Elagolix is a second generation new non-peptide $(\mathrm{GnRH})$ antagonist, highly potent antagonist orally active and rapidly bioavailable after administration that is being developed by Abbott Laboratories (Abbott) in collaboration with Neurocrine Biosciences $[16,17]$. It Finalizing the Phase III for endometriosis and finalizing Phase II for uterine leiomyoma with opportunity to be its first and only approved oral treatment for uterine leiomyoma [18]. This promising compound inhibits gonadotropin releasing hormone (GnRh) receptors in the pituitary gland leading to a dose dependent suppression of LH, FSH and estradiol. Consequently, suppression of E2 is more prolonged at higher doses. Pituitary suppression is maintained for only a portion of the day, and baseline gonadotropin levels return by 24 hours [19].

These properties suggest that elagolix may enable dose-related pituitary and gonadal suppression in premenopausal women as part of treatment strategies for reproductive hormone-dependent disease states [19]. To date, elagolix has been studied in 18 clinical trials totaling more than 1,000 subjects.

Elagolix seems to be well tolerated for multiple-doses up to 200; rapidly absorbed after oral administration, with median time of maximum plasma concentration (Tmax) values ranging from $0.5-1 \mathrm{~h}$, the primary metabolite (NBI-61962) appear in the serum rapidly after administration [19].

The therapeutic window of E2 levels for suppression of endometriosis using is attainable at a dose of $100-150 \mathrm{mg} /$ day with serum estradiol remained between $20-50 \mathrm{pg} / \mathrm{ml}$ [20]. This is 
supported by Barberi RL findings which showed that E2 levels between 30-50 pg/ml are effective in inducing endometrial atrophy [21]. The Elagolix therapeutic dose for management of uterine fibroid has yet to be determined.

\section{Selective Estrogen Receptor Modulators (SERMS)}

Selective estrogen receptor modulators (SERMs) are non-steroidal estrogen receptor ligands that display tissue-specific agonist-antagonist estrogenic actions. They are used frequently in the treatment and prevention of estrogen receptor-positive carcinoma of the breast in addition to their use as ovulation induction agents [22,23]. Tamoxifen is one of the oldest known SERMs, but it may potentially cause endometrial carcinoma due to its partial agonistic effect on the endometrium [24]. There are no randomized controlled trials that have investigated the potential role of Tamoxifen in the treatment of uterine fibroids; however, a few case reports have suggested that it actually increases leiomyoma growth [22, 25]. Raloxifene is another SERM that can be theoretically considered to be a candidate therapeutic option for uterine fibroids. Raloxifene only slightly affected collagen biosynthesis in control myometrium cells; however, it significantly inhibited collagen biosynthesis in leiomyoma cells [26] and exerted its action at the transcriptional level [27]. A newly developed SERM, "Lasofoxifene", is currently awaiting FDA approval. However, the results of early trials suggest that there were no significant benefits compared to raloxifene for the skeleton, breast, heart, or reproductive tract [28, 29].

\subsection{Mechanism of action}

The most probable hypothesis that explain SERMs' mechanism of action is that they induce changes in estrogen receptors, which result in differential expression of specific estrogenregulated genes in different tissues [30]. Every member of the SERM family has its own individual characteristics, which depend on its structure, the type of estrogen receptor they bind to, and the set of molecules that interact with its estrogen receptor/SERM complex in affected cells, and these characteristics result in either agonistic or antagonistic activity [31]. SERMS could potentially provide therapeutic benefits by having antagonistic effects at uterine myometrial level and by preventing ovarian stimulation which has been achieved in rat studies. The difference in activity of SERMS is based on the structure activity relationships (SAR) [32].

\subsection{SERMs and treatment of uterine fibroids}

All SERMs, with their estrogen blocking activity, would be theoretically expected to exert at least some therapeutic effect on uterine fibroids. Raloxifene has been showed to enhance the shrinkage of uterine fibroids in postmenopausal women [33, 34]. However, a recent report from Italy that addressed the effect of raloxifene on uterine leiomyoma showed that the leiomyoma size in premenopausal women who were administered daily 60-mg doses of raloxifene over a 2-year period exhibited no change in leiomyoma size [35].

\subsection{Adverse events}

Tamoxifen is not recommended for women with a prior history of deep venous thrombosis, pulmonary embolus, stroke, or transient ischemic attack because it increases the risk of 
ischemic stroke, particularly in women who are 50 years of age or older. Additionally, the risk of uterine/endometrial cancer was approximately doubled with tamoxifen use [36], and the risk of superficial thrombophlebitis was three times higher [24, 37]. Some of these side effects could be explained by the inhibition of cellular glutamine uptake, oxidative stress and the induction of apoptosis [38]. SERMs are seldom used for the treatment of uterine fibroids [26].

\section{Aromatase inhibitors}

Aromatase inhibitors (AI) significantly block both ovarian and peripheral estrogen production within 1 day of treatment [39]. Letrozole suppressed the production of estrogens, particularly estrone and estradiol, by $76-79 \%$ compared to their baseline levels [40]. The underlying mechanism is the inhibition of the aromatase enzyme, which is the enzyme that catalyzes the conversion of androgenic substances into estrogens [41]. Recent reports have suggested that aromatase is expressed to a greater extent in uterine leiomyoma tissues of African-American women compared to Caucasian women, which may contribute to the higher incidence of ULMs in African American women [42]. Aromatase inhibitors have been shown to be effective against fibroids in limited short term studies with dosing regimens that included $2.5 \mathrm{mg}$ per day of letrozole and $1 \mathrm{mg}$ per day of anastrozole [43]. One of the major concerns with the use of aromatase inhibitors is the reported bone loss with prolonged use, which necessitates the concomitant use of oral contraceptive pills or progesterone [44]. A recently published RCT compared the effects of three months of aromatase inhibitor (letrozole) to that of three months of gonadotropin-releasing hormone agonist (triptorelin) on uterine leiomyoma volume and hormonal status [45]. The results showed an advantage of the rapid onset of action of AIs in addition to the avoidance of the flare ups that initially occurs with GnRHa. Both treatment options induced significant shrinkage of the uterine fibroids and improvement in leiomyoma-associated symptoms [45]. The mean reduction of leiomyoma volume with 3 months use of anastrazole is $55.7 \%$ [46]. The authors suggested that aromatase inhibitors should be considered in women with fibroids on a short term basis or in women who want to avoid surgical intervention to preserve their potential fertility [47]. Another concern with the use of AIs as a treatment option for uterine leiomyoma is its off-label use, which mandates a thorough review with patients prior to the initiation of the therapy [44]. Several RCTs are underway that would hopefully add to our understanding of the potential promising role of AIs in the treatment of uterine leiomyomas [36].

\section{Antiprogesterones}

Estrogen has traditionally been considered to be the most important stimulus for leiomyoma growth and numerous studies that included cell culture and animal models supported this concept [48]. Surprisingly, recent findings suggest that volume maintenance and growth of human ULMs are also heavily progesterone-dependent, and hence anti-progesterone could reverse leiomyoma growth effects [16, 49]. One potential link between the effects of the two key steroid hormones on ULMs is that estradiol induced the expression of the progesterone receptor and supported progesterone action on leiomyoma tissue [48]. Clinical findings also support these laboratory observations; studies have involved the evaluation of mifepristone (RU 486) [50-52], azoprisnil [43, 49], and more recently, CDB-2914 and CDB-4124 (CDB: Contraceptive Development Branch) [53]. 


\subsection{Mifepristone}

Mifepristone (RU486), a well-known oral anti-progesterone compound, has been used for more than 20 years for multiple clinical indications [45, 54-56]. It has recently been evaluated as a potential therapeutic agent for uterine fibroids with a dose that ranges from $5 \mathrm{mg}$ to $50 \mathrm{mg}$ over a 3-month period $[29,57,58]$. Mifepristone reduced leiomyoma size (26\% to $74 \%)$ and improved leiomyoma-related symptoms (63\% to 100\% induction of amenorrhea). Reported side effects included transient elevations in transaminases, which occurred in $4 \%$ of cases as well as endometrial hyperplasia and was detected in $28 \%$ of the women who were screened with endometrial biopsies [59]. However, these studies were mostly preliminary with limited numbers of subjects and therefore, larger randomized well-controlled trials that include thorough monitoring of liver function and endometrial histology are required to conclusively determine the safety and efficacy of this treatment modality.

\subsection{Asoprisnil}

Asoprisnil (J867, BAY86-5294) is an investigational selective progesterone receptor modulator (SPRM) that was developed for the treatment of progesterone-sensitive myomata. It induces unique morphological changes and is associated with inhibited proliferation of the endometrium and leiomyomata. These changes may lead to amenorrhea, which is usually encountered with its use [43, 60,61]. Asoprisnil is a tissue selective molecule that binds to the progesterone receptors with a three-fold greater affinity than endogenous progesterone [57]. It reduces the uterine and leiomyoma volumes in a dosedependent manner while achieving remarkable decreases in menorrhagia scores in women with menorrhagia [62]. Amenorrhea rates also increased as the dose of asoprisnil was increased [58, 60]. When asoprisnil was administered daily for longer than 3-4 months, significant endometrial thickening and unusual histological appearance of the endometrial glands occurred [29].

\subsection{Telapristone acetate/ CDB-4124 (proposed trade names, proellex, progenta)}

CDB-4124 is another SPRM, but it is a relatively pure progesterone antagonist. It was studied in recent years for the treatment of uterine fibroids and is still being evaluated to address its safety and dose parameters in premenopausal women [63]. Limited information or publications are currently available on the various clinical trials that have investigated CDB-4124; these studies have either been completed or were terminated due to adverse liver-related events according to the www.clinical trials.gov website. New clinical trials using lower doses of CDB-4124 have recently been approved by the FDA.

\subsection{Ulipristal/CDB-2914 (VA 2914, ellaOne, ella)}

Ulipristal is an FDA-approved selective progesterone receptor modulator (SPRM) that is indicated for emergency contraception. It is structurally similar to mifepristone and seems to be effective in the treatment of uterine fibroids. It is associated with a reduction in pain, bleeding and leiomyoma size between $17-24 \%$ [64], as well as an improvement in quality of life [65]. However, data on long-term treatment are lacking and similar to other SPRMs, ulipristal may be associated with endometrial thickening and endometrial hyperplasia [29, $39,66]$. Large randomized well-controlled clinical trials are needed to evaluate the utility of ulipristal for potential clinical treatment of uterine fibroids [39]. 


\section{Somatostatin analogues}

Increasing evidence has demonstrated a role for growth factors, such as insulin growth factor I (IGF-I) and IGF-II, in the initiation and progression of uterine fibroids [67-70]. Leiomyoma tissue expresses higher levels of IGF-I/IGF-II receptors compared to normal adjacent myometrium [62, 69]. Additionally, these tissues secrete their own IGF-1, probably for autocrine and paracrine use [70]. From a clinical perspective, it has been recently reported that patients with high levels of growth hormone (acromegalic patients) have a higher prevalence of uterine fibroids than the general population [71]. Lanreotide, which is a long-acting somatostatin analogue that has been shown to reduce growth hormone secretion, has also recently been evaluated in seven women with uterine fibroids in Italy [72]. Interestingly, lanreotide induced a $42 \%$ mean myoma volume reduction within a 3month period. These results show that somatostatin analogues may potentially be a new therapy for uterine fibroids [73]. The treatment with somatostatin analogues for diseases other than leiomyoma appears to be safe and is usually well tolerated with some reports of gallstone formation [74, 75]. However, the lacking of clinical trials which test the long term use of somatostatin analogues along with the severe and adverse health implications such as decreased life expectancy due to accelerated heart disease which observed in adults with growth hormone deficiency may hinder its future use for leiomyoma treatment.

\section{Cabergoline}

Carbergoline is a well-known dopamine agonist that is effectively used in the treatment of prolactinoma and for the inhibition of lactation. A recent study [76] evaluated carbergoline as a therapeutic option for uterine fibroids. The rational for such an approach lies in its effect as an inhibitory agent on GnRH release. A group in Iran published a preliminary study in 2007 [76] that favored the use of carbergoline as a medical treatment of uterine fibroids on which they reported a volume reduction of about $50 \%$ with 6 weeks use [65]. The same group performed a subsequent study that compared carbergoline with diphereline, which is a gonadotropin-releasing hormone agonist [77]. They reported comparable results in terms of the shrinkage of the fibroids and the improvement in the sonographic, clinical, and intraoperative outcomes [77]. These findings warrant future larger controlled trials to clearly assess the potential use of carbergoline in the treatment of uterine fibroids.

\section{Danazol}

Danazol is a synthetic steroid that inhibits steroidogenesis through multi-enzymatic actions in addition to its suppressor effect on sex hormone binding globulin [78]. It reportedly induced a significant $24 \%$ volume reduction $[79,80]$. However, a recent Cochrane study failed to identify any randomized controlled trials that compared danazol to placebo or any other medical therapy in women with uterine fibroids [81].

\subsection{Gestrinone}

Gestrinone is a steroid that possesses anti-estrogen receptor and anti-progesterone receptor properties in various tissues, including the endometrium [82]. A recent report from Italy evaluated the use of Gestrinone in the treatment of premenopausal women with uterine fibroids at a dose of $2.5 \mathrm{mg}$ twice per week over a 6-month period [82]. The authors reported 
a $32 \% \pm 10 \%$ reduction in uterine volume [82]. A subsequent study reported up to $60 \%$ leiomyoma shrinkage in size [83]. Gestrinone is a contraceptive agent and also exhibits several unfavorable side effects, such as mild androgenicity, weight gain, seborrhea, acne, hirsutism, and occasional hoarseness.

\subsection{Vitamin D (VitD)}

Data from our laboratory demonstrate that Vitamin D (VitD) is an antifibrotic factor and inhibits growth and induces apoptosis in cultured human leiomyoma cells through the down-regulation of PCNA, CDK1, and BCL-2 and suppresses COMT expression and activity in human leiomyoma cells [84-86]. We have also recently demonstrated similar effects in the Eker rat model of uterine fibroids [87]. Another group in Finland demonstrated that Vitamin D inhibit growth of both myometrial and leiomyoma cells in vitro [88] The growth inhibition was concentration dependent and the level of inhibition was statistically significant with the concentration of $1000 \mathrm{nM}$.

In a separate study from our group, the correlation between low serum levels of VitD and the increased risk of having symptomatic uterine fibroids were evaluated [89, 90]. We measured both the biologically active 1, 25 dihydroxyvitamin D3 and the precursor 25hydroxyvitamin D3 in the serum from African American and white women with fibroids as well as normal healthy controls. Interestingly, then observed that 1, 25 dihydroxyvitamin D3 is significantly lower in women with fibroids compared to normal healthy controls; additionally, it has been detected that lower levels of total serum 25-hydroxyvitamin D3 in women with fibroids compared to healthy controls. These findings were observed both in African American women and in Caucasian women.

The aim of the study was to determine whether serum levels of VitD correlated with disease severity in women with symptomatic uterine fibroids. The study population consisted of 67 patients who had detailed repeated pelvic ultrasound evaluations over a 2-year period with specific measurements of the total uterine volume and the volume of the individual leiomyoma lesions. The patients also had detailed laboratory analysis including serum 25 hydroxy Vit D3 levels. As shown in (Fig I), a statistically significant negative correlation between the low serum Vit $\mathrm{D}$ levels and the total uterine leiomyoma volume $(\mathrm{P}<.05)$ as well as the number of leiomyoma lesions/uterus $(\mathrm{P}<0.05)$ was detected [63]. Taken together, our preliminary results suggest a strong dose-response correlation between lower serum Vit D levels and increased severity of uterine fibroids. This presents an opportunity for the potential use of Vit D or its potent analogues as novel treatment options or for the prevention of uterine fibroids.

To date there is no randomized controlled trials had been implemented to prospectively assess the efficacy of Vit D in the management of uterine fibroids.

\section{Epigallocatechin Gallate (EGCG), green tea extract}

Tea is one of the most widely consumed beverages all over the world. Both the green tea and the black tea are derived from the leaves of the plant 'Camellia sinensis' the most significant components of which are phytochemicals, of which Green tea is thoroughly studied for its health benefits. 
A typical green tea beverage, prepared in a proportion of $1 \mathrm{~g}$ leaf to $100 \mathrm{ml}$ water in a 3-min brew, usually contains $250-350 \mathrm{mg}$ tea solids, and catechins account for $30-42 \%$ of the dry weight of the solids [91]. It has been demonstrated that tea constituents exhibit various biological and pharmacological properties such anti-carcinogenic, antioxidative, antiallergic, anti-virus, anti-hypertensive, anti-atherosclerosis, anti-cardiovascular disease and anti-hypercholesterolemic activities [92, 93].

The major green tea catechins are epigallocatechin-3-gallate (EGCG), epigallocatechin (EGC), epicatechin-3-gallate (ECG) and epicatechin. Catechines are a group of bioflavonoids that exhibit antioxidant and anti-inflammatory capacity. Chemically, catechines are polyhydroxylated with water-soluble characteristics [94]. Epigallocatechin gallate (EGCG), which is the principal catechin, comprises $>40 \%$ of the total polyphenolic mixture of green tea catechins [95], Grapes also contain polyphenols and catechins such as EGCG [96]. Epigallocatechin gallate exhibits various biological activities including potent antioxidant and anti-inflammation capacity [97].

EGCG appears to block each stage of tumorgenesis by modulating signaling pathways involved in cell proliferation, transformation, inflammation, and oxidative stress, which are clearly involved in pathogenesis of various tumors including uterine fibroids [98].

In our laboratory, we studied the effect and potential mechanisms of EGCG action on human leiomyoma (HuLM) cells [99], as we assayed cell proliferation and apoptosis, the protein levels of PCNA, CDK4, BCL2, and BAX which examined by Western blot analysis, and we found that Epigallocatechin gallate inhibits the proliferation of HuLM cells and induces apoptosis. These results suggest that EGCG may be a potential anti-uterine fibroid agent acting through multiple signal transduction pathways [100]. Additional validation of these findings was achieved using orally administered EGCG to shrink pre-existing subcutaneous leiomyoma lesions in immune-compromised mice [99]. Previous studies have shown that EGCG inhibited the growth of various human cancer cells, such as epidermoid carcinoma cells [101], hepatoma cells [102], prostate carcinoma cells [103], and breast cancer cells [104]. Those findings motivated us to initiate a clinical trial to evaluate the promising clinical role of EGCG in women with symptomatic uterine fibroids.

\section{References}

[1] Stewart, E.A., Uterine fibroids. Lancet, 2001. 357(9252): p. 293-8.

[2] Sankaran, S. and I.T. Manyonda, Medical management of fibroids. Best Pract Res Clin Obstet Gynaecol, 2008. 22(4): p. 655-76.

[3] Parker, W.H., Etiology, symptomatology, and diagnosis of uterine myomas. Fertil Steril, 2007. 87(4): p. 725-36.

[4] Drinville Jamie S, M.S., Benign Disorders of the Uterine Corpus" (Chapter), in CURRENT Diagnosis \& Treatment Obstetrics \& Gynecology, 10e, N.L. DeCherney AH, Editor. 2010.

[5] Sunkara, S.K., et al., The effect of intramural fibroids without uterine cavity involvement on the outcome of IVF treatment: a systematic review and meta-analysis. Hum Reprod, 2010. 25(2): p. 418-29.

[6] Flynn, M., et al., Health care resource use for uterine fibroid tumors in the United States. Am J Obstet Gynecol, 2006. 195(4): p. 955-64. 
[7] Zhang, Y., et al., Acupuncture for uterine fibroids. Cochrane Database Syst Rev, 2010(1): p. CD007221.

[8] Viswanathan, M., et al., Management of uterine fibroids: an update of the evidence. Evid Rep Technol Assess (Full Rep), 2007(154): p. 1-122.

[9] Marshall, L.M., et al., A prospective study of reproductive factors and oral contraceptive use in relation to the risk of uterine leiomyomata. Fertil Steril, 1998. 70(3): p. 432-9.

[10] Chiaffarino, F., et al., Use of oral contraceptives and uterine fibroids: results from a casecontrol study. Br J Obstet Gynaecol, 1999. 106(8): p. 857-60.

[11] Parazzini, F., et al., Oral contraceptive use and risk of uterine fibroids. Obstet Gynecol, 1992. 79(3): p. 430-3.

[12] Friedman, A.J., et al., Long-term medical therapy for leiomyomata uteri: a prospective, randomized study of leuprolide acetate depot plus either oestrogen-progestin or progestin 'add-back' for 2 years. Hum Reprod, 1994. 9(9): p. 1618-25.

[13] Orsini, G., L. Laricchia, and M. Fanelli, [Low-dose combination oral contraceptives use in women with uterine leiomyomas]. Minerva Ginecol, 2002. 54(3): p. 253-61.

[14] Venkatachalam, S., J.S. Bagratee, and J. Moodley, Medical management of uterine fibroids with medroxyprogesterone acetate (Depo Provera): a pilot study. J Obstet Gynaecol, 2004. 24(7): p. 798-800.

[15] Murat Naki, M., et al., Levonorgestrel-releasing intrauterine device insertion ameliorates leiomyoma-dependent menorrhagia among women of reproductive age without a significant regression in the uterine and leiomyoma volumes. Fertil Steril. 94(1): p. 371-4.

[16] Yoshida, S., et al., Cell-type specific actions of progesterone receptor modulators in the regulation of uterine leiomyoma growth. Semin Reprod Med, 2010. 28(3): p. 260-73.

[17] Chen, C., et al., Discovery of sodium $R-(+)-4-\{2-[5-(2-f l u o r o-3-m e t h o x y p h e n y l)-3-(2-f l u o r o-6-$ [trifluoromethyl]be nzyl)-4-methyl-2,6-dioxo-3,6-dihydro-2H-pyrimidin-1-yl]-1phenylethylamino \}butyrate (elagolix), a potent and orally available nonpeptide antagonist of the human gonadotropin-releasing hormone receptor. J Med Chem, 2008. 51(23): p. 7478-85.

[18] Abbott, Future abbott pipeline 2011.

[19] Struthers, R.S., et al., Suppression of gonadotropins and estradiol in premenopausal women by oral administration of the nonpeptide gonadotropin-releasing hormone antagonist elagolix. J Clin Endocrinol Metab, 2009. 94(2): p. 545-51.

[20] Dmowski, W., Advances in the treatment of endometriosis - The potential of Elagolix. US Obstetrics \& Gynecology, 2008. 3(1): p. 21-23.

[21] Barbieri, R.L., Hormone treatment of endometriosis: the estrogen threshold hypothesis. Am J Obstet Gynecol, 1992. 166(2): p. 740-5.

[22] Lethaby, A.E. and B.J. Vollenhoven, An evidence-based approach to hormonal therapies for premenopausal women with fibroids. Best Pract Res Clin Obstet Gynaecol, 2008. 22(2): p. 307-31.

[23] Black, L.J., et al., Raloxifene (LY139481 HCI) prevents bone loss and reduces serum cholesterol without causing uterine hypertrophy in ovariectomized rats. J Clin Invest, 1994. 93(1): p. 63-9.

[24] Temin, S., American Society of Clinical Oncology clinical practice guideline update on the use of pharmacologic interventions including tamoxifen, raloxifene, and aromatase inhibition for breast cancer risk reduction. Gynecologic Oncology, 2009. 115(1): p. 132-134. 
[25] Fisher, B., et al., Endometrial cancer in tamoxifen-treated breast cancer patients: findings from the National Surgical Adjuvant Breast and Bowel Project (NSABP) B-14. J Natl Cancer Inst, 1994. 86(7): p. 527-37.

[26] Wu, T., X. Chen, and L. Xie, Selective estrogen receptor modulators (SERMs) for uterine leiomyomas. Cochrane Database Syst Rev, 2007(4): p. CD005287.

[27] Zbucka, M., et al., Mechanism of collagen biosynthesis up-regulation in cultured leiomyoma cells. Folia Histochem Cytobiol, 2007. 45 Suppl 1: p. S181-5.

[28] Becker, C., Another selective estrogen-receptor modulator for osteoporosis. N Engl J Med, 2010. 362(8): p. 752-4.

[29] Spitz, I.M., Clinical utility of progesterone receptor modulators and their effect on the endometrium. Curr Opin Obstet Gynecol, 2009. 21(4): p. 318-24.

[30] Mitlak, B.H. and F.J. Cohen, In search of optimal long-term female hormone replacement: the potential of selective estrogen receptor modulators. Horm Res, 1997. 48(4): p. 155-63.

[31] Dutertre, M. and C.L. Smith, Molecular mechanisms of selective estrogen receptor modulator (SERM) action. J Pharmacol Exp Ther, 2000. 295(2): p. 431-7.

[32] Richardson, T.I., et al., Structure-activity relationships of SERMs optimized for uterine antagonism and ovarian safety. Bioorg Med Chem Lett, 2007. 17(13): p. 3544-9.

[33] Palomba, S., et al., Effects of raloxifene treatment on uterine leiomyomas in postmenopausal women. Fertil Steril, 2001. 76(1): p. 38-43.

[34] Palomba, S., et al., Antiproliferative and proapoptotic effects of raloxifene on uterine leiomyomas in postmenopausal women. Fertil Steril, 2005. 84(1): p. 154-61.

[35] Premkumar, A., et al., Gynecologic and hormonal effects of raloxifene in premenopausal women. Fertil Steril, 2007. 88(6): p. 1637-44.

[36] Aromatase Inhibitors for Treatment of Uterine Leiomyomas. Clinical Trials.gov 2010 July 28, 2009 [cited 2010 07-09-2010]; Available from:

http://clinicaltrials.gov/ct2/show/NCT00945360?term=aromatase+inhibitors++fi broid\&rank=1.

[37] Ettinger, B., et al., Reduction of vertebral fracture risk in postmenopausal women with osteoporosis treated with raloxifene: results from a 3-year randomized clinical trial. Multiple Outcomes of Raloxifene Evaluation (MORE) Investigators. JAMA, 1999. 282(7): p. 637-45.

[38] Todorova, V.K., et al., Tamoxifen and raloxifene suppress the proliferation of estrogen receptor-negative cells through inhibition of glutamine uptake. Cancer Chemother Pharmacol, 2010.

[39] Fiscella, K. and S. Eisinger, CDB-2914 for uterine leiomyomata treatment: a randomized controlled trial. Obstet Gynecol, 2008. 112(3): p. 707; author reply 707-8.

[40] Iveson, T.J., et al., Phase I study of the oral nonsteroidal aromatase inhibitor CGS 20267 in healthy postmenopausal women. J Clin Endocrinol Metab, 1993. 77(2): p. 324-31.

[41] Smith, I.E. and M. Dowsett, Aromatase inhibitors in breast cancer. N Engl J Med, 2003. 348(24): p. 2431-42.

[42] Ishikawa, H., et al., High aromatase expression in uterine leiomyoma tissues of AfricanAmerican women. J Clin Endocrinol Metab, 2009. 94(5): p. 1752-6.

[43] Williams, A.R., et al., The effects of the selective progesterone receptor modulator asoprisnil on the morphology of uterine tissues after 3 months treatment in patients with symptomatic uterine leiomyomata. Hum Reprod, 2007. 22(6): p. 1696-704. 
[44] Bedaiwy, M.A., Lui, J., Long-term management of endometriosis: Medical therapy and treatment of infertility. Sexuality, Reproduction and menopause, 2010. 8(3): p. 5.

[45] Baird, D.T., et al., Mifepristone: a novel estrogen-free daily contraceptive pill. Steroids, 2003. 68(10-13): p. 1099-105.

[46] Varelas, F.K., et al., The effect of anastrazole on symptomatic uterine leiomyomata. Obstet Gynecol, 2007. 110(3): p. 643-9.

[47] Parsanezhad, M.E., et al., A randomized, controlled clinical trial comparing the effects of aromatase inhibitor (letrozole) and gonadotropin-releasing hormone agonist (triptorelin) on uterine leiomyoma volume and hormonal status. Fertil Steril, 2010. 93(1): p. 192-8.

[48] Ishikawa, H., et al., Progesterone is essential for maintenance and growth of uterine leiomyoma. Endocrinology, 2010. 151(6): p. 2433-42.

[49] Wilkens, J., et al., Effects of the selective progesterone receptor modulator asoprisnil on uterine artery blood flow, ovarian activity, and clinical symptoms in patients with uterine leiomyomata scheduled for hysterectomy. J Clin Endocrinol Metab, 2008. 93(12): p. 466471.

[50] Carbonell Esteve, J.L., et al., Mifepristone for the treatment of uterine leiomyomas: a randomized controlled trial. Obstet Gynecol, 2008. 112(5): p. 1029-36.

[51] Fiscella, K., et al., Effect of mifepristone for symptomatic leiomyomata on quality of life and uterine size: a randomized controlled trial. Obstet Gynecol, 2006. 108(6): p. 1381-7.

[52] Engman, M., et al., Mifepristone for treatment of uterine leiomyoma. A prospective randomized placebo controlled trial. Hum Reprod, 2009. 24(8): p. 1870-9.

[53] Attardi, B.J., et al., In vitro antiprogestational/antiglucocorticoid activity and progestin and glucocorticoid receptor binding of the putative metabolites and synthetic derivatives of CDB-2914, CDB-4124, and mifepristone. J Steroid Biochem Mol Biol, 2004. 88(3): p. 277-88.

[54] Engman, M., et al., The effect of mifepristone on breast cell proliferation in premenopausal women evaluated through fine needle aspiration cytology. Hum Reprod, 2008. 23(9): p. 2072-9.

[55] Lalitkumar, P.G., et al., Mifepristone, but not levonorgestrel, inhibits human blastocyst attachment to an in vitro endometrial three-dimensional cell culture model. Hum Reprod, 2007. 22(11): p. 3031-7.

[56] Sharts-Engel, N.C., The RU 486 story: the French experience. MCN Am J Matern Child Nurs, 1992. 17(1): p. 56.

[57] Brahma, P.K., K.M. Martel, and G.M. Christman, Future directions in myoma research. Obstet Gynecol Clin North Am, 2006. 33(1): p. 199-224, xiii.

[58] Chwalisz, K., et al., Role of nonhuman primate models in the discovery and clinical development of selective progesterone receptor modulators (SPRMs). Reprod Biol Endocrinol, 2006. 4 Suppl 1: p. S8.

[59] Steinauer, J., et al., Systematic review of mifepristone for the treatment of uterine leiomyomata. Obstet Gynecol, 2004. 103(6): p. 1331-6.

[60] Chwalisz, K., et al., A randomized, controlled trial of asoprisnil, a novel selective progesterone receptor modulator, in women with uterine leiomyomata. Fertil Steril, 2007. 87(6): p. 1399-412.

[61] Chwalisz, K., et al., The effects of 1-month administration of asoprisnil (J867), a selective progesterone receptor modulator, in healthy premenopausal women. Hum Reprod, 2005. 20(4): p. 1090-9. 
[62] Boehm, K.D., et al., Expression of the insulin-like and platelet-derived growth factor genes in human uterine tissues. Mol Reprod Dev, 1990. 27(2): p. 93-101.

[63] Abdelraheem, M.S. and A. Al-Hendy, Serum vitamin D3 level inversely correlates with total fibroid tumor burden in women with symptomatic uterine fibroid. Fertility and Sterility, 2010. 94(4): p. S74.

[64] Nieman, L.K., et al., Efficacy and tolerability of CDB-2914 treatment for symptomatic uterine fibroids: a randomized, double-blind, placebo-controlled, phase IIb study. Fertil Steril, 2011. 95(2): p. 767-72 e1-2.

[65] Melli, M.S., L. Farzadi, and E.O. Madarek, Comparison of the effect of gonadotropinreleasing hormone analog (Diphereline) and Cabergoline (Dostinex) treatment on uterine myoma regression. Saudi Med J, 2007. 28(3): p. 445-50.

[66] Levens, E.D., et al., CDB-2914 for uterine leiomyomata treatment: a randomized controlled trial. Obstet Gynecol, 2008. 111(5): p. 1129-36.

[67] Hoppener, J.W., et al., Expression of insulin-like growth factor-I and -II genes in human smooth muscle tumours. EMBO J, 1988. 7(5): p. 1379-85.

[68] Gloudemans, T., et al., Insulin-like growth factor gene expression in human smooth muscle tumors. Cancer Res, 1990. 50(20): p. 6689-95.

[69] Norstedt, G., A. Levinovitz, and H. Eriksson, Regulation of uterine insulin-like growth factor I $m R N A$ and insulin-like growth factor II mRNA by estrogen in the rat. Acta Endocrinol (Copenh), 1989. 120(4): p. 466-72.

[70] Rein, M.S., et al., The secretion of insulin-like growth factors I and II by explant cultures of fibroids and myometrium from women treated with a gonadotropin-releasing hormone agonist. Obstet Gynecol, 1990. 76(3 Pt 1): p. 388-94.

[71] Cohen, O., B. Schindel, and R. Homburg, Uterine leiomyomata--a feature of acromegaly. Hum Reprod, 1998. 13(7): p. 1945-6.

[72] Nilsson, C.G., et al., Intrauterine contraception with levonorgestrel: a comparative randomised clinical performance study. Lancet, $1981.1(8220 \mathrm{Pt} 1)$ : p. 577-80.

[73] De Leo, V., et al., Administration of somatostatin analogue reduces uterine and myoma volume in women with uterine leiomyomata. Fertil Steril, 2001. 75(3): p. 632-3.

[74] Feelders, R.A., et al., Medical therapy of acromegaly: efficacy and safety of somatostatin analogues. Drugs, 2009. 69(16): p. 2207-26.

[75] Davies, P.H., et al., Long-term therapy with long-acting octreotide (Sandostatin-LAR®) for the management of acromegaly. Clinical Endocrinology, 1998. 48(3): p. 311-316.

[76] Sivin, I. and J. Stern, Health during prolonged use of levonorgestrel 20 micrograms/d and the copper TCu 380Ag intrauterine contraceptive devices: a multicenter study. International Committee for Contraception Research (ICCR). Fertil Steril, 1994. 61(1): p. 70-7.

[77] Sayyah-Melli, M., et al., Comparison of the effect of gonadotropin-releasing hormone agonist and dopamine receptor agonist on uterine myoma growth. Histologic, sonographic, and intra-operative changes. Saudi Med J, 2009. 30(8): p. 1024-33.

[78] Steingold, K.A., et al., Danazol inhibits steroidogenesis by the human ovary in vivo. Fertil Steril, 1986. 45(5): p. 649-54.

[79] De Leo, V., A. la Marca, and G. Morgante, Short-term treatment of uterine fibromyomas with danazol. Gynecol Obstet Invest, 1999. 47(4): p. 258-62.

[80] La Marca, A., et al., Hemodynamic effect of danazol therapy in women with uterine leiomyomata. Fertil Steril, 2003. 79(5): p. 1240-2.

[81] Ke, L.Q., et al., Danazol for uterine fibroids. Cochrane Database Syst Rev, 2009(3): p. CD007692. 
[82] La Marca, A., et al., Gestrinone in the treatment of uterine leiomyomata: effects on uterine blood supply. Fertil Steril, 2004. 82(6): p. 1694-6.

[83] Coutinho, E.M., Treatment of large fibroids with high doses of gestrinone. Gynecol Obstet Invest, 1990. 30(1): p. 44-7.

[84] Sharan, C., et al., Vitamin D inhibits proliferation of human uterine leiomyoma cells via catechol-O-methyltransferase. Fertility and Sterility. In Press, Corrected Proof.

[85] Halder, S.K., J.S. Goodwin, and A. Al-Hendy, 1,25-Dihydroxyvitamin D3 reduces TGFbeta3-induced fibrosis-related gene expression in human uterine leiomyoma cells. J Clin Endocrinol Metab, 2011. 96(4): p. E754-62.

[86] Sharan, C., et al., Vitamin D inhibits proliferation of human uterine leiomyoma cells via catechol-O-methyltransferase. Fertil Steril, 2011. 95(1): p. 247-53.

[87] Halder, S.K., C. Sharan, and A. Al-Hendy, Vitamin D treatment induces dramatic shrinkage of uterine leiomyomas growth in the Eker rat model. Fertility and Sterility, 2010. 94(4): p. S75-S76.

[88] Blauer, M., et al., Vitamin D inhibits myometrial and leiomyoma cell proliferation in vitro. Fertil Steril, 2009. 91(5): p. 1919-25.

[89] Halder, S.K., S. Goodwin, and A. Al-Hendy, Vitamin D exhibits antiestrogenic effects in human uterine leiomyoma cells. Fertility and Sterility, 2010. 94(4): p. S219-S220.

[90] Halder, S.K., et al., 1, 25 dihydroxyvitamin D3 disorganizes actin fibers in human immortalized uterine leiomyoma cells. Fertility and Sterility, 2009. 92(3): p. S127-S128.

[91] Khan, N. and H. Mukhtar, Tea polyphenols for health promotion. Life Sci, 2007. 81(7): p. 519-33.

[92] Kuriyama, S., et al., Green tea consumption and mortality due to cardiovascular disease, cancer, and all causes in Japan: the Ohsaki study. JAMA, 2006. 296(10): p. 1255-65.

[93] Lambert, J.D. and C.S. Yang, Cancer chemopreventive activity and bioavailability of tea and tea polyphenols. Mutat Res, 2003. 523-524: p. 201-8.

[94] Joo Eun, C., et al., Amplification of antioxidant activity of catechin by polycondensation with acetaldehyde. Biomacromolecules, 2004. 5(1): p. 113-8.

[95] Lin, J.-K., Y.-C. Liang, and S.-Y. Lin-Shiau, Cancer chemoprevention by tea polyphenols through mitotic signal transduction blockade. Biochemical Pharmacology, 1999. 58(6): p. 911-915.

[96] Zern, T.L., et al., Grape polyphenols exert a cardioprotective effect in pre- and postmenopausal women by lowering plasma lipids and reducing oxidative stress. J Nutr, 2005. 135(8): p. 1911-7.

[97] Mukhtar, H. and N. Ahmad, Green tea in chemoprevention of cancer. Toxicol Sci, 1999. 52(2 Suppl): p. 111-7.

[98] Khan, N., et al., Targeting multiple signaling pathways by green tea polyphenol (-)epigallocatechin-3-gallate. Cancer Res, 2006. 66(5): p. 2500-5.

[99] Dong, Z., et al., Antiproliferative and proapoptotic effects of epigallocatechin gallate on human leiomyoma cells. Fertility and Sterility, 2010. 94(5): p. 1887-1893.

[100] Zhang, D., et al., Antiproliferative and proapoptotic effects of epigallocatechin gallate on human leiomyoma cells. Fertil Steril, 2010. 94(5): p. 1887-93.

[101] Ahmad, N., P. Cheng, and H. Mukhtar, Cell Cycle Dysregulation by Green Tea Polyphenol Epigallocatechin-3-Gallate. Biochemical and Biophysical Research Communications, 2000. 275(2): p. 328-334. 
[102] Chen, C., et al., Activation of antioxidant-response element (ARE), mitogen-activated protein kinases (MAPKs) and caspases by major green tea polyphenol components during cell survival and death. Arch Pharm Res, 2000. 23(6): p. 605-12.

[103] Gupta, S., et al., Growth Inhibition, Cell-Cycle Dysregulation, and Induction of Apoptosis by Green Tea Constituent (-)-Epigallocatechin-3-gallate in Androgen-Sensitive and Androgen-Insensitive Human Prostate Carcinoma Cells. Toxicology and Applied Pharmacology, 2000. 164(1): p. 82-90.

[104] Tang, Y., et al., Epigallocatechin-3 gallate induces growth inhibition and apoptosis in human breast cancer cells through survivin suppression. Int J Oncol, 2007. 31(4): p. 705-11. 


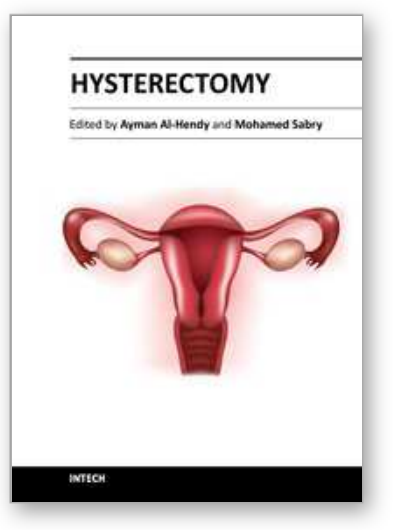

\author{
Hysterectomy \\ Edited by Dr. Ayman Al-Hendy
}

ISBN 978-953-51-0434-6

Hard cover, 426 pages

Publisher InTech

Published online 20, April, 2012

Published in print edition April, 2012

This book is intended for the general and family practitioners, as well as for gynecologists, specialists in gynecological surgery, general surgeons, urologists and all other surgical specialists that perform procedures in or around the female pelvis, in addition to intensives and all other specialities and health care professionals who care for women before, during or after hysterectomy. The aim of this book is to review the recent achievements of the research community regarding the field of gynecologic surgery and hysterectomy as well as highlight future directions and where this field is heading. While no single volume can adequately cover the diversity of issues and facets in relation to such a common and important procedure such as hysterectomy, this book will attempt to address the pivotal topics especially in regards to safety, risk management as well as pre- and post-operative care.

\title{
How to reference
}

In order to correctly reference this scholarly work, feel free to copy and paste the following:

Mohamed Y. Abdel-Rahman, Mohamed Sabry and Ayman Al-Hendy (2012). Medical Treatment of Fibroid to Decrease Rate of Hysterectomy, Hysterectomy, Dr. Ayman Al-Hendy (Ed.), ISBN: 978-953-51-0434-6, InTech, Available from: http://www.intechopen.com/books/hysterectomy/medical-treatment-of-fibroid-to-decrease-rateof-hysterectomy

\section{INTECH}

open science | open minds

\author{
InTech Europe \\ University Campus STeP Ri \\ Slavka Krautzeka 83/A \\ 51000 Rijeka, Croatia \\ Phone: +385 (51) 770447 \\ Fax: +385 (51) 686166 \\ www.intechopen.com
}

\author{
InTech China \\ Unit 405, Office Block, Hotel Equatorial Shanghai \\ No.65, Yan An Road (West), Shanghai, 200040, China \\ 中国上海市延安西路65号上海国际贵都大饭店办公楼405单元 \\ Phone: +86-21-62489820 \\ Fax: $+86-21-62489821$
}


(C) 2012 The Author(s). Licensee IntechOpen. This is an open access article distributed under the terms of the Creative Commons Attribution 3.0 License, which permits unrestricted use, distribution, and reproduction in any medium, provided the original work is properly cited. 